\title{
Titanium-zirconium narrow-diameter versus titanium regular-diameter implants for anterior and premolar single crowns: 3-year results of a randomized controlled clinical study.
}

Ioannidis, Alexis ; Gallucci, German O ; Jung, Ronald E ; Borzangy, Sary ; Hämmerle, Christoph H F ; Benic, Goran I

Abstract: AIM To test whether titanium-zirconium (Ti-Zr) $3.3 \mathrm{~mm}$ diameter implants perform differently from titanium (Ti) $4.1 \mathrm{~mm}$ diameter implants with respect to marginal bone level (MBL) and clinical parameters. MATERIAL AND METHODS Forty patients in need of a single-implant crown in the anterior or premolar regions were enrolled in two centres. Following random allocation, either a Ti-Zr or a Ti implant was inserted. Porcelainfused-to-metal crowns were inserted 6 months after implantation. Implant survival, change in MBL, clinical parameters, change in mid-facial mucosa and papilla levels, and the occurrence of biological and technical complications were assessed at the 3-year follow-up. RESULTS At 3 years, 32 of the 40 included patients were examined $(15 \mathrm{Ti}, 17 \mathrm{Ti}-\mathrm{Zr})$. There were no implant failures. From the implant placement to 3 years, the median change in mean MBL amounted to $0.21 \mathrm{~mm}$ (mean: -0.31) in the Ti group and $0.10 \mathrm{~mm}$ (mean: -0.40$)$ in the Ti-Zr group. There were no significant differences between the groups with respect to the change in MBL, the change in mucosa levels, and the occurrence of complications. CONCLUSIONS Ti-Zr implants with $3.3 \mathrm{~mm}$ diameter used for the support of single crowns in the anterior and the premolar regions did not differ from Ti implants with 4.1 $\mathrm{mm}$ diameter regarding the clinical performance over a 3-year period. This article is protected by copyright. All rights reserved.

DOI: https://doi.org/10.1111/jcpe.12468

Posted at the Zurich Open Repository and Archive, University of Zurich ZORA URL: https://doi.org/10.5167/uzh-113483

Journal Article

Accepted Version

Originally published at:

Ioannidis, Alexis; Gallucci, German O; Jung, Ronald E; Borzangy, Sary; Hämmerle, Christoph H F; Benic, Goran I (2015). Titanium-zirconium narrow-diameter versus titanium regular-diameter implants for anterior and premolar single crowns: 3-year results of a randomized controlled clinical study. Journal of Clinical Periodontology, 42(11):1060-1070.

DOI: https://doi.org/10.1111/jcpe. 12468 


\section{Titanium-zirconium narrow-diameter versus titanium regular-}

\section{2 diameter implants for anterior and premolar single crowns: 3-}

\section{3 year results of a randomized controlled clinical study}

4 Alexis loannidis ${ }^{1}$, German O. Gallucci ${ }^{2}$, Ronald E. Jung ${ }^{1}$, Sary Borzangy ${ }^{2,3}$, Christoph H.F.

5 Hämmerle ${ }^{1}$, Goran I. Benic ${ }^{1}$

7 1: Clinic of Fixed and Removable Prosthodontics and Dental Material Science, Center of

8 Dental Medicine, University of Zurich, Zurich, Switzerland

9 2: Department of Restorative Dentistry and Biomaterials Sciences, Harvard School of Dental

10 Medicine, Boston, USA

11 3: Department of Substitutive Dental Sciences, College of Dentistry, Taibah University, Al

12 Madinah Al Munawwarah, Kingdom of Saudi Arabia

14 Key words: dental implants, titanium-zirconium, titanium, narrow, diameter, crown, fixed

15 partial denture, humans, randomized controlled trial, survival, radiographic

16 Running title: Ti-Zr narrow- vs. Ti regular-diameter

17

18 Address for correspondence:

Dr. Goran I. Benic

Clinic of Fixed and Removable Prosthodontics and Dental Material Science

Center of Dental Medicine

University of Zurich

Plattenstrasse 11

8032 Zurich, Switzerland

Tel: +41 446343252 


\section{Abstract}

2 Aim: To test whether titanium-zirconium (Ti-Zr) $3.3 \mathrm{~mm}$ diameter implants perform differently

3 from titanium ( $\mathrm{Ti}) 4.1 \mathrm{~mm}$ diameter implants with respect to marginal bone level (MBL) and

4 clinical parameters.

5 Material and Methods: Forty patients in need of a single-implant crown in the anterior or

6 premolar regions were enrolled in two centres. Following random allocation, either a $\mathrm{Ti}-\mathrm{Zr}$ or

7 a Ti implant was inserted. Porcelain-fused-to-metal crowns were inserted 6 months after

8 implantation. Implant survival, change in MBL, clinical parameters, change in mid-facial

9 mucosa and papilla levels, and the occurrence of biological and technical complications were

10 assessed at the 3-year follow-up.

11 Results: At 3 years, 32 of the 40 included patients were examined $(15 \mathrm{Ti}, 17 \mathrm{Ti}-\mathrm{Zr})$. There

12 were no implant failures. From the implant placement to 3 years, the median change in mean

$13 \mathrm{MBL}$ amounted to $0.21 \mathrm{~mm}$ (mean: -0.31 ) in the Ti group and $0.10 \mathrm{~mm}$ (mean: -0.40 ) in the

$14 \mathrm{Ti}-\mathrm{Zr}$ group. There were no significant differences between the groups with respect to the

15 change in MBL, the change in mucosa levels, and the occurrence of complications.

16 Conclusions: $\mathrm{Ti}-\mathrm{Zr}$ implants with $3.3 \mathrm{~mm}$ diameter used for the support of single crowns in

17 the anterior and the premolar regions did not differ from $\mathrm{Ti}$ implants with $4.1 \mathrm{~mm}$ diameter

18 regarding the clinical performance over a 3-year period.

19 


\section{Introduction}

Placing dental implants into native bone or in conjunction with bone augmentation

3 procedures is a predictable treatment option to prosthetically restore the edentulous jaw 4 regions (Jung et al., 2012, Benic et al., 2009, Hammerle et al., 2002). Due to the reduced 5 bucco-oral dimension of the edentulous alveolar ridge, the prosthetically driven implant 6 placement is frequently associated with the presence of peri-implant bone dehiscences and 7 fenestrations. In terms of mesio-distal gap dimension, an adequate distance between teeth and implants is required to reduce the amount of subsequent bone resorption and recession

9 of the papillae (Esposito et al., 1993, Tarnow et al., 2000). The challenging clinical situations 10 with limited mesio-distal amount of space or reduced ridge width can be overcome by using 11 narrow-diameter implants (Davarpanah et al., 2000).

A recent systematic review of clinical trials found survival rates of narrow-diameter $13(3.0-3.5 \mathrm{~mm})$ implants ranging from $89 \%$ to $100 \%$ (Klein et al., 2014). The meta-analysis of 14 the data showed no statistically significant differences in implant survival between implants 15 with $3.3-3.5 \mathrm{~mm}$ diameter and those with conventional diameter $(3.75-4.1 \mathrm{~mm})$. It was, 16 however, found that there is insufficient evidence on the success rates for implants with 17 narrow diameter (Klein et al., 2014). It is known that fatigue fractures of narrow-diameter 18 implants may occur after a long period of loading (Zinsli et al., 2004). The risk of 19 biomechanical problems and the limited knowledge of their clinical behaviour should, 20 therefore, be taken into account when using implants with narrow diameter (Bornstein et al. $212014)$.

22 The strength of titanium (Ti) implants can be increased, by alloying $\mathrm{Ti}$ with other 23 metals, such as zirconium (Kobayashi et al., 1995, Grandin et al., 2012). A titanium24 zirconium ( $\mathrm{Ti}-\mathrm{Zr}$ ) alloy, made of $83-87 \% \mathrm{Ti}$ and $13-17 \% \mathrm{Zr}$, was developed and introduced for 25 the fabrication of narrow-diameter implants (Berner et al., 2009). Preclinical investigations 26 revealed that $\mathrm{Ti}-\mathrm{Zr}$ implants perform similar to $\mathrm{Ti}$ implants with respect to osseointegration 27 (Thoma et al., 2011, Gottlow et al., 2012, Saulacic et al., 2012, Anchieta et al., 2013, Wen et 28 al., 2013). 
The clinical performance of narrow-diameter $\mathrm{Ti}-\mathrm{Zr}$ implants was investigated in

2 several previous clinical trials (Chiapasco et al., 2012, Benic et al., 2013, Anchieta et al., 3 2013) In those studies high survival and success rates for $\mathrm{Ti}-\mathrm{Zr}$ narrow-diameter implants

4 were observed after short periods of observation. A recent randomized controlled trial 5 compared narrow-diameter $\mathrm{Ti}-\mathrm{Zr}$ and $\mathrm{Ti}$ implants for the support of mandibular overdentures 6 (Al-Nawas et al., 2012). In this study no differences were found between $\mathrm{Ti}-\mathrm{Zr}$ and $\mathrm{Ti}$ 7 implants with respect to the change in marginal bone level (MBL), the implant survival and 8 the success rate after 3 years of observation (Quirynen et al., 2014). However, there is 9 insufficient comparative evidence available on the clinical performance of narrow-diameter $10 \mathrm{Ti}-\mathrm{Zr}$ implants for the support of fixed partial dentures in the load bearing jaw regions.

11 Therefore, the primary aim of the present randomized controlled clinical trial was to 12 test whether $\mathrm{Ti}-\mathrm{Zr} 3.3 \mathrm{~mm}$ diameter implants, placed to support single crowns in the anterior 13 and the premolar regions, render different results from $\mathrm{Ti} 4.1 \mathrm{~mm}$ diameter implants with 14 respect to the change in MBL over a 3-year period. The null hypothesis was that the 15 treatment modalities do not differ with respect to the change in MBL from the implant 16 placement to the 3-year follow-up. In addition, the implant survival, the soft tissue parameters 17 and the complication rate were assessed. 


\section{Material and Methods}

This article is reported according to the CONSORT guidelines for reporting parallel

3 group randomized trials (Moher et al., 2010).

4

\section{Study design}

This study was designed as a prospective randomized controlled clinical trial with two parallel study groups and a duration period of 5 years. The study was conducted at two

8 centres (Clinic of Fixed and Removable Prosthodontics and Dental Material Science, Center

9 of Dental Medicine, University of Zurich, Zurich, Switzerland and Department of Restorative

10 Dentistry and Biomaterials Sciences, Harvard School of Dental Medicine, Boston, MA, USA).

11 The clinical protocol was approved by the respective local ethical committees.

\section{Study population}

14 Each centre recruited 20 subjects for a total of 40 patients in need of an implant15 supported crown for the restoration of a single-tooth gap in the anterior or the premolar 16 regions of upper or lower jaw.

17 The subjects had to fulfil the following inclusion criteria:

$18 \cdot \geq 18$ years of age

19 - No medical history in which any elective oral surgical intervention would be 20 contraindicated

21 - No heavy smoking (>20 cigarettes per day)

22 - No active periodontal disease

23 - Full-mouth plaque score (FMPS) and full-mouth bleeding score (FMBS) $<25 \%$

24 - Need of an implant-supported crown at a single-tooth gap in regions 11-15, 21-25, 31$25 \quad 35,41-45$ (FDI)

26 - Presence of mesial and distal natural teeth 


\section{8}

- Adequate quantity of native bone to allow the placement of an implant with $4.1 \mathrm{~mm}$ diameter and $8 \mathrm{~mm}$ length with at least $2 \mathrm{~mm}$ of distance to the mandibular alveolar canal. The pre-operative assessment of the apico-coronal amount of bone available was performed by means of a panoramic radiograph.

Need of primary bone augmentation and absence of primary stability at the time of implant placement were considered exclusion criteria.

A signed informed consent was obtained from all the patients prior to any study treatments.

\section{Randomization and allocation concealment}

All patients were randomly allocated to one of the two treatment modalities according to a computer-generated randomization list. Two separated lists were created for the two study centers. To generate the allocation sequence, a permuted-block randomization with block sizes of 4 and allocation ratio of 1:1 was applied. In the case that two or more sites per patient were available, fulfilling the inclusion criteria, one gap was selected by throwing a die. Allocation to the study groups was concealed by using sealed envelopes until the time of surgical procedure that required the preparation of the implant bed.

\section{Treatment procedures}

The time sequence of interventions and assessments is represented in Fig. 1. All investigators participating in the study were experienced in implant placement and bone augmentation procedures. Before the study initiation, all participating clinicians attended a training session to standardize the patient selection and the therapeutic procedure and to calibrate the assessment techniques.

The placement of implants was performed either as type 2, type 3 or type 4 procedure (Hammerle et al., 2004). Prior to implant insertion, the patients received antibiotics $(2 \times 750$ mg amoxicillin) and non-steroidal analgesics/antiphlogistics. The surgery was performed under local anaesthesia. A crestal incision and, if needed, a vertical release incision were 
1 performed and the mucoperiostal flaps were elevated. In the case that the amount of bone

2 was found to be insufficient for implant placement, the patient was considered ineligible for

3 the study and an alternative treatment following good clinical standards was offered. The

4 implant bed was prepared according to the manufacturer's instruction for the placement of

5 Straumann ${ }^{\circledast}$ Bone Level implants (Institut Straumann AG, Basel, Switzerland).

$6 \quad$ One of the following randomly assigned implants was inserted:

7 - Test group: a Ti-Zr $3.3 \mathrm{~mm}$ diameter implant (Straumann ${ }^{\circledast}$ Bone Level, Roxolid ${ }^{\circledast}$,

$8 \quad$ SLActive $^{\circledast}$, Institut Straumann AG)

9 - Control group: a Ti $4.1 \mathrm{~mm}$ diameter implant (Straumann ${ }^{\circledR}$ Bone Level, Ti, SLActive ${ }^{\varpi}$,

10 Institut Straumann AG).

12 The implant stability was assessed by mechanical testing with a hand instrument (e.g.

13 periodontal probe). In the event that the implant lacked primary stability (visible mobility on

14 mechanical testing), the subject was excluded from the study and an alternative treatment

15 was offered following good clinical standards. Peri-implant bone dehiscences, fenestrations,

16 infrabony defects measuring $>0.5 \mathrm{~mm}$ of width, and thin bone plates were grafted with

17 particulated deproteinized bovine bone mineral (BioOss ${ }^{\circledR}$ Spongiosa Granules; Geistlich

18 Pharma AG, Wolhusen, Switzerland) and covered with a native collagen membrane

19 (BioGide ${ }^{\circledast}$; Geistlich Pharma AG). If needed, the membrane was fixed by using resorbable

20 pins (Inion GTR ${ }^{\mathrm{TM}}$, Inion Ltd., Tampere, Finland). A cover screw was placed and the mucosal

21 flaps were sutured using ePTFE non-resorbable monofilament sutures (Gore-Tex ${ }^{\circledR}$, Gore,

22 Flagstaff, AZ, USA). All the implants healed in a submerged position. The patients were 23 instructed to rinse the oral cavity twice daily with $0.2 \%$ chlorhexidine-digluconate and 24 analgesics (mefenamic acid $500 \mathrm{mg}$ ) were prescribed for the first 3 days according to the 25 individual needs. In cases of guided bone regeneration, the patients received antibiotics for 5 26 days ( $3 \times 750 \mathrm{mg} /$ day amoxicillin). The sutures were removed 7 days after implant 
1 placement. Post-surgical examinations including supra-gingival cleaning were performed 2

2 and 6 weeks after implant insertion.

3 Three months after the implant placement, the re-entry surgery was performed under local

4 anaesthesia. After crestal incision and flap elevation, cover screws were replaced by healing

5 abutments. When necessary, provisional crowns were inserted to condition the peri-implant

6 soft tissue. The final porcelain-fused-to-metal single screw- or cement-retained crowns were

7 placed 6 months after the implantation. All the patients were recalled for the follow-up

8 assessment 1 and 3 years after the implant placement (Fig. 2).

\section{Outcome variables}

11 Implant survival

12 Implant survival was assessed at the 3-year follow-up. The implant survival was 13 defined as the implant being in place and stable. The stability of the implant-supported 14 reconstruction and, if necessary, of the implant were assessed by mechanical testing with a 15 hand instrument.

Marginal bone level

Periapical radiographs were taken immediately after implant insertion, at 6 months, at

191 year and at 3 years. Standardized radiographs were taken by using individualized X-ray 20 film holder devices. The individualization of the film holder was performed with a bite21 registration material (R-SI-Line ${ }^{\circledast}$ Metal-Bite $^{\circledast}$, R-dental $\mathrm{GmbH}$, Hamburg, Germany). The film 22 was positioned parallel to the implant axis and the X-ray beam directed perpendicular to the 23 implant. The radiographs were digitized as jpeg files and imported in the Image 1.43 open24 source software (National Institute of Health, Bethesda, MD, USA). A calibrated investigator, 25 who was unaware of the treatment strategy and the aim of the study, evaluated all the 26 radiographic images.

27 The marginal bone level (MBL) was assessed on the mesial and on the distal aspect 28 of each implant by measuring the distance between the implant shoulder and first bone-to- 
1 implant contact. The known distance between implant threads was used for the calibration of

2 the images. Mesial and distal MBL values were averaged to one value per implant. The

3 changes in MBL from implant placement to 6,12 and 36 months examinations were

4 calculated. A negative change of MBL denoted a loss of marginal bone.

5

6 Clinical parameters

7 At the 1- and 3-year follow-up examinations, the following variables were assessed:

8 - Full-mouth plaque score (FMPS) at six sites per tooth/implant (O'Leary et al., 1972)

9 - Full-mouth bleeding on probing score (FMBS) at six sites per tooth/implant (Ainamo and

$10 \quad$ Bay, 1975)

11 - Plaque control record (PCR) at six sites per study implant (O'Leary et al., 1972)

12 - Bleeding on probing score (BOP) at six sites per study implant (Ainamo and Bay, 1975)

13 - Probing pocket depth (PPD) at six sites per study implant

14 - Width of the keratinized mucosa $(\mathrm{KM})$ at the mid-buccal aspect of the study implant

Mid-facial mucosa and papilla levels

After the insertion of the final crown (6 months after implantation), at the 1-and 3-year examinations, the levels of the mid-facial mucosa and of the inter-proximal papillae were

19 assessed. The tangent to the incisal edge/buccal cusp of the implant-supported crown was 20 used as the reference line. The measurements were performed with a periodontal probe and 21 the values approximated to the nearest $0.5 \mathrm{~mm}$.

The changes in mucosa levels from 6 months to 1 and 3 years were calculated. A negative value denoted a reduction in soft tissue level.

Adverse events and complications

The occurrence of adverse events (AE) and biological and technical complications

27 was recorded at each study visit. The following biological complications were assessed:

28 implant mobility, persistent subjective complaints, continuous peri-implant radiolucency, peri- 
1 implant infection with suppuration (Buser et al., 1990). Peri-implantitis was defined as bone

2 loss $>2 \mathrm{~mm}$ in combination with a positive BOP recording (Sanz et al., 2012). The list of the

3 technical complications included: implant fracture, abutment fracture, fracture of the

4 veneering ceramic, loosening of the abutment screw, fracture of the abutment screw. If

5 needed, appropriate treatment was performed and the patient was monitored until the AE or

6 complication was resolved.

8 Statistical analysis

The statistical analysis was performed with SPSS Statistics 20.0 (SPSS Inc., Chicago, IL, USA) and Stat $X$ act 11.0 (Cytel, Cambridge, MA, USA).

The primary parameter was the change of MBL from the implant placement to the 3-

12 year examination. The sample size calculation was based on two independent groups, a

13 normal distribution and the two-sample t-test. To detect a difference of $0.5 \mathrm{~mm}$ with a 14 standard deviation (SD) of $0.5 \mathrm{~mm}$ (power: $80 \%$, significance level: 0.05 ), 17 patients per 15 group (total of 34 patients) were required. To compensate for possible drop-outs, the sample 16 size was increased to 20 patients per group (total of 40 patients).

For the statistical analysis the six values around each implant for PCR, BOP and PPD and the two values for MBL and papilla level at the mesial and distal aspect were averaged

19 to one value each. For MBL and papilla level, the mesial, the distal and the mean values 20 were analyzed separately. For discrete variables, the absolute and the relative frequencies 21 were calculated. For continuous parameters, the data distributions were represented with 22 boxplots and the data were reported by using means, standard deviations (SD), ranges, 23 medians, and interquartile ranges (IQR). The non-parametric Mann-Whitney test was applied to detect differences between the groups because of non-normality of the data. To 25 analyse the centre effect on the primary endpoint, the non-parametric Hodges-Lehmann 26 estimate together with the non-parametric 95\% confidence intervals $(\mathrm{Cl})$ were used. For 27 implant survival, the $95 \% \mathrm{Cl}$ for the true survival was computed. Results of tests with $\mathrm{p}$ - 
1 values $\leq 0.05$ were considered statistically significant. No correction for multiple testing was

2 performed for the analyses of the secondary endpoints.

\section{Results}

Patients

A total number of 40 patients were included in this study from January 2010 to

8 December 2010. Of these, 20 were randomized to the Ti group and 20 to the $\mathrm{Ti}-\mathrm{Zr}$ group.

9 There were no significant differences between the treatment groups with respect to the

10 following parameters: patient gender, patient age, smoking, implant location and time point of 11 implant placement after tooth extraction ( $p>0.05)$ (Table S1). At 3 years, 32 out of the 40 12 included patients attended the follow-up examination, rendering a recall rate of $80 \%$. Two 13 subjects had moved and were classified as lost to follow-up between 6 and 12 months.

14 Between 1 and 3 years, 6 patients had moved or passed away and could not be recruited for 15 the follow-up examination.

Implant survival

At the 1-year follow-up, $18 \mathrm{Ti}$ and $20 \mathrm{Ti}-\mathrm{Zr}$ implants were evaluated. At 3 years, 15 out of $20 \mathrm{Ti}$ implants $(75 \%)$ and 17 out of $20 \mathrm{Ti}-\mathrm{Zr}$ implants (85\%) were examined. During the

20 entire study observation period, no implant failures were recorded, yielding a 3-year implant

21 survival rate of $100 \%$ for both the $\mathrm{Ti}(95 \% \mathrm{Cl}: 78 \% ; 100 \%)$ and the $\mathrm{Ti}-\mathrm{Zr}$ groups $(95 \% \mathrm{Cl}$ : $2280 \% ; 100 \%)$.

Marginal bone level

From the implant placement to the 3-year follow-up, the median change of mean MBL 
1 SD: $-0.40 \pm 0.93 \mathrm{~mm}$ ) in the Ti-Zr group with no significant difference between the groups ( $p$ $2=0.720)$ (Table 1, Fig. 3).

The centre effect on the change in MBL from the implant placement to the 3-year examination was not statistically significant $(p=0.058)$. When analysing the data for each centre separately, the differences between the treatment groups were not statistically significant (Boston: 95\% Cl: -0.09, $1.04 \mathrm{~mm}$; Zurich: 95\% Cl: $-0.51,0.24 \mathrm{~mm}$ ).

From the 1-year to the 3-year examination, the median change in mean MBL measured $-0.01 \mathrm{~mm}$ (mean \pm SD: $0.14 \pm 0.59 \mathrm{~mm}$ ) for the Ti implants and $-0.04 \mathrm{~mm}$ (mean \pm SD: $-0.05 \pm 0.41 \mathrm{~mm}$ ) for the Ti-Zr implants. The difference between the groups was not statistically significant $(p=0.692)$ (Table 1, Fig. 3).

When analysing the changes in the mesial and in the distal MBL separately, there

12 were no significant differences between the $\mathrm{Ti}$ and the $\mathrm{Ti}-\mathrm{Zr}$ groups for the period from 13 implant placement to the 3-year examination (mesial: $p=0.880$; distal: $p=0.637$ distal) and 14 the period from 1 to 3 years (mesial: $p=0.417$; distal: $p=0.777$ ).

The frequency distributions of the changes in MBL from the implant placement to the 1-year examination were described in a previous publication (Benic et al., 2013). The corresponding results from implant placement to the 3-year follow-up are represented in Figure 4. One year after implant placement, there were two $\mathrm{Ti}-\mathrm{Zr}$ implants with $>2 \mathrm{~mm}$ of

19 bone loss at the mesial aspect and one Ti implant with $>2 \mathrm{~mm}$ of bone loss at the distal 20 aspect. One of the two Ti-Zr implants could not be examined at 3 years because the patient 21 was lost to follow-up. At the 3-year examination, two Ti-Zr implants and no Ti implants were 22 observed with $>2 \mathrm{~mm}$ of bone loss.

Clinical parameters

The results of FMPS, PCR, BOP and KM are presented in Table 2. At 3 years, there were no statistically significant differences in FMPS, PCR, BOP and KM between the groups $27(p>0.05)$. The median FMBS amounted to $12 \%$ (mean \pm SD: $15.7 \pm 11.6 \%$ ) for Ti implants 
1 and $4 \%$ (mean \pm SD: $6.9 \pm 7.3 \%$ ) for Ti-Zr implants. The difference in FMBS between the

2 groups reached statistical significance $(p=0.028)$.

Mid-facial mucosa and papilla levels

The results of the changes in facial mucosa and papilla levels are presented in Table

3. From the 6-month to the 1-year examination, the median change in mid-facial mucosa

7 level measured $0 \mathrm{~mm}$ (mean \pm SD: $0.2 \pm 0.6 \mathrm{~mm}$ ) for the $\mathrm{Ti}$ implants and $0 \mathrm{~mm}(0.0 \pm 0.8$

$8 \mathrm{~mm}$ ) for the Ti-Zr implants. The difference between the groups did not reach statistical 9 significance $(p=0.480)$. From the crown insertion (6 months after implantation) to the 3-year 10 follow-up, the median change of mid-facial mucosa level amounted to $0.5 \mathrm{~mm}$ (mean $\pm \mathrm{SD}$ : $110.3 \pm 1.1 \mathrm{~mm}$ ) in the Ti group and $-0.5 \mathrm{~mm}$ (mean $\pm \mathrm{SD}:-0.3 \pm 0.9 \mathrm{~mm}$ ) in the Ti-Zr group 12 with no significant difference between the groups $(p=0.281)($ Table 3$)$.

13 In terms of change in mesial and distal papilla levels, there were no significant 14 differences between the groups ( $p>0.05)$ (Table 3).

Adverse events and complications

Postoperative complications were described in a previous publication (Benic et al., 18 2013).

19 From 6 months to 3 years, there were no cases of implant mobility, persistent 20 subjective complaints, continuous peri-implant radiolucency, or peri-implant infection with 21 suppuration. At 3 years, one Ti-Zr implant was diagnosed with peri-implantitis $(1 / 17=5.9 \%)$ 22 according to the specific definition (Sanz et al., 2012). Another Ti-Zr implant was affected by 23 peri-implantitis at the 1-year follow-up. This patient could not be recruited for the 3-year 24 examination.

At the 3-year follow-up, it bled on probing at totally 18 implants. Therefore, according 26 to the specific definition (Sanz et al., 2012) peri-implant mucositis was diagnosed at $10 \mathrm{Ti}$ 27 implants and at $8 \mathrm{Ti}-\mathrm{Zr}$ implants. 
At the 3-year follow-up, two technical complications were recorded in the Ti-Zr group

$2 \quad(2 / 17=11.8 \%)$ : one polishable fracture of the veneering ceramic and one loosening of the

3 abutment screw. At 3 years, one polishable chipping of the veneering ceramic was observed

4 in the Ti group $(1 / 15=6.7 \%)$.

\section{Discussion}

The results of the present randomized controlled clinical study suggest that $\mathrm{Ti}-\mathrm{Zr} 3.3$

$9 \mathrm{~mm}$ diameter and $\mathrm{Ti} 4.1 \mathrm{~mm}$ diameter two-piece implants do not differ with respect to the

10 change in marginal bone level from the implant placement to the 3 -year examination. There

11 were no implant failures during the 3-year observation period. Furthermore, there were no

12 differences between the $\mathrm{Ti}-\mathrm{Zr}$ narrow-diameter and the $\mathrm{Ti}$ regular-diameter implants

13 regarding the soft tissue parameters and the changes of the peri-implant mucosal level.

14 These results are in accordance with the data reported in previous clinical studies 15 investigating $\mathrm{Ti}-\mathrm{Zr} 3.3 \mathrm{~mm}$ diameter implants. In a recent randomized controlled, double16 blind, split-mouth trial, $3.3 \mathrm{~mm}$-diameter two-piece $\mathrm{Ti}$ and $\mathrm{Ti}-\mathrm{Zr}$ implants were compared 17 (Quirynen et al., 2014). All the patients received one $\mathrm{Ti}$ and one $\mathrm{Ti}-\mathrm{Zr}$ implant in the 18 interforaminal region of the edentulous mandible. Implants were loaded after 6-8 weeks with 19 removable locator-retained over-dentures. Of the 91 treated patients, 75 completed the 320 year follow-up. One $\mathrm{Ti}-\mathrm{Zr}$ and two $\mathrm{Ti}$ implants were lost, yielding a 3-year survival rate of $2198.7 \%$ for Ti-Zr implants and $97.3 \%$ for Ti implants. With respect to the implant survival and 22 the change in MBL, there were no statistically significant differences between the groups.

23 The change of mean MBL between implant placement and 3 years reached $-0.78 \mathrm{~mm}$ for Ti$24 \mathrm{Zr}$ implants and $-0.60 \mathrm{~mm}$ for $\mathrm{Ti}$ implants. In a pilot clinical study, 22 patients received $\mathrm{Ti}-\mathrm{Zr}$ one-piece $3.3 \mathrm{~mm}$ diameter implants for the support of fixed reconstructions in the anterior 26 and the premolar regions (Barter et al., 2012). The Ti-Zr narrow-diameter implants were 27 splinted either to regular- or to wide-diameter implants. At 2 years, the survival rate of the Ti- 
$1 \mathrm{Zr}$ implants reached $95.2 \%$ and the mean change of MBL was $-0.33 \mathrm{~mm}$. Another clinical 2 study assessed the use of narrow-diameter one-piece $\mathrm{Ti}$ and $\mathrm{Ti}-\mathrm{Zr}$ implants placed in the 3 posterior region of the jaw to support single crowns (Tolentino et al., 2014). In this 4 randomized controlled trial, 21 patients received a $3.3 \mathrm{~mm}$-diameter Ti-Zr implant and 21 5 subjects were treated with a $3.3 \mathrm{~mm}$-diameter Ti implant. During the first 6 weeks after 6 implant placement, one implant was lost in each group. At the 1-year examination, the 7 survival and the success rates amounted to $95.2 \%$ for both groups (Tolentino et al., 2014). In the present study, no implant fractures occurred. At 3 years, two technical complications were observed in the test group, corresponding to a technical complication rate of $11.8 \%$. In a recent systematic review, the cumulative 5 -year rate for technical 11 complication rate for single implant crowns reached $8.8 \%$ (Jung et al., 2012). Abutment- and 12 screw-loosening, loss of retention and fracture of the veneering material were the most 13 frequent technical complications (Jung et al., 2012). These data are in accordance with the 14 findings of the present clinical trial.

The main limitation of the present study is the fact that the treatment groups differed regarding the implant material and the implant diameter. Therefore, no conclusions can be drawn on implant diameter or implant material separately. Moreover, the difference in two variables represents a potential confounder since both parameters may be associated with the study outcome. In this context it has to be emphasized that several preclinical and clinical trials found no differences between $\mathrm{Ti}-\mathrm{Zr}$ and $\mathrm{Ti}$ implants with respect to osseointegration

21 and change in the marginal bone level (Thoma et al., 2011, Al-Nawas et al., 2012, Quirynen 22 et al., 2014, Gottlow et al., 2012, Saulacic et al., 2012, Anchieta et al., 2013, Wen et al., 2013). As far as the clinical relevance is concerned, the main question is whether narrowdiameter implants made of $\mathrm{Ti}-\mathrm{Zr}$ represent a valid alternative to the $\mathrm{Ti}$ regular-diameter implants, which are considered the gold standard for single tooth gaps in the anterior and the premolar regions. The present study aimed to answer this question. Another limitation of the

27 present study is given by the fact that implants with and without GBR of peri-implant defects 28 were included. This variable represents a potential confounder of the primary outcome. 
2 not differ from the implants placed into pristine bone with respect to the interproximal 3 marginal bone levels (Benic and Hammerle, 2014, Benic et al., 2009, Jung et al., 2013, 4 Mayfield et al., 1998, Zumstein et al., 2012). Moreover, in the current trial the treatment groups did not differ regarding the distribution of cases with GBR.

The results of the present study are promising, since the use of narrow-diameter

7 implants has the potential to preserve the peri-implant tissue and, consequently, to reduce

8 the need for bone grafting procedures (Papadimitriou et al., 2014, Caneva et al., 2010).

9 However, more clinical long-term investigations are needed reporting survival and success

10 rates of narrow-diameter implants. When using implants with narrow diameter, it is therefore,

11 recommended to take into account the potential risk of biomechanical complications.

12

13

14

15

16

\section{Conclusions}

Within the limitation of the present randomized controlled trial it can be concluded that 19 the Ti-Zr $3.3 \mathrm{~mm}$ diameter implants do not differ from the Ti $4.1 \mathrm{~mm}$ diameter implants with 20 respect to the change in $\mathrm{MBL}$ from the implant placement to the 3-year examination. From 1

21 to 3 years, the implants under investigation exhibited stable MBL. During the 3-year 22 observation period there were no implant failures and no device-related serious adverse 23 events. Moreover, no differences regarding the soft tissue parameters and the changes in 24 the mucosa levels were found between the groups. 
1 Acknowledgements: The investigators gratefully acknowledge PhD Caroline Lustenberger 2 for the assistance in analysing the data.

3

4 Conflict of interest: Dres. Benic, Gallucci, Weber, Jung and Prof. Hämmerle provided 5 lectures or consultations, which were reimbursed from Institut Straumann AG. The authors 6 report no financial interests related to any products involved in this study. This study was 7 supported by an unrestricted grant from ITI Foundation, by the Clinic of Fixed and 8 Removable Prosthodontics and Dental Material Science, Center of Dental Medicine, 9 University of Zurich, Switzerland, and by the Department of Restorative Dentistry and 10 Biomaterials Sciences, Harvard School of Dental Medicine. 


\section{Tables and Figures}

\section{Tables}

3 Table 1. (a) Results of the marginal bone level at the implant placement, at 6 months, at 1

4 year and at 3 years. (b) Results of the change in marginal bone level from the implant 5 placement to 1 year, from implant placement to 3 years and from 1 year to 3 years (negative 6 values represent bone loss).

\begin{tabular}{|c|c|c|c|c|c|c|c|c|c|c|c|c|}
\hline & & \multicolumn{5}{|c|}{ Ti 4.1} & \multicolumn{5}{|c|}{ Ti-Zr 3.3} & \multirow[b]{2}{*}{$\mathrm{p}$-value * } \\
\hline & & $\mathrm{n}$ & Mean \pm SD & Median & IQR & Range & $\mathrm{n}$ & Mean \pm SD & Median & IQR & Range & \\
\hline \multicolumn{13}{|l|}{ (a) Marginal bone level (mm) } \\
\hline Implant placement & Mesial & 20 & $-0.07 \pm 0.24$ & 0 & 0 & -1.00 to 0.00 & 20 & $-0.08 \pm 0.15$ & 0 & 0.10 & -0.56 to 0 & 0.351 \\
\hline & Mean & & $-0.06 \pm 0.14$ & 0 & 0 & -0.50 to 0.00 & & $-0.09 \pm 0.12$ & 0.05 & 0.18 & -0.38 to 0 & 0.086 \\
\hline 6 months & Mesial & 20 & $-0.27 \pm 0.31$ & 0.15 & 0.28 & -1.28 to 0.00 & 20 & $-0.33 \pm 0.30$ & 0.22 & 0.53 & -0.95 to 0.11 & 0.396 \\
\hline & Distal & & $-0.29 \pm 0.42$ & 0.21 & 0.50 & -1.62 to 0.10 & & $-0.40 \pm 0.42$ & 0.38 & 0.63 & -1.21 to 0.20 & 0.184 \\
\hline 1 year & Mesial & 18 & $-0.41 \pm 0.47$ & 0.24 & 0.83 & -1.28 to 0.23 & 20 & $-0.50 \pm 0.75$ & 0.24 & 0.42 & -2.85 to 0.18 & 0.874 \\
\hline & Distal & & $-0.51 \pm 0.68$ & 0.31 & 0.69 & -2.26 to 0.12 & & $-0.51 \pm 0.58$ & 0.26 & 0.58 & -1.78 to 0.03 & 0.942 \\
\hline & Mean & & $-0.46 \pm 0.50$ & 0.28 & 0.44 & -1.73 to -0.09 & & $-0.50 \pm 0.63$ & 0.30 & 0.40 & -2.15 to 0.10 & 0.965 \\
\hline 3 years & Mesial & 15 & $-0.28 \pm 0.50$ & 0.16 & 0.93 & -1.23 to 0.34 & 17 & $-0.42 \pm 0.70$ & 0.19 & 0.56 & -2.13 to 0.33 & 0.748 \\
\hline & Distal & & $-0.48 \pm 0.68$ & 0.27 & 0.84 & -1.88 to 0.34 & & $-0.59 \pm 1.14$ & 0.33 & 0.71 & -4.07 to 0.30 & 0.910 \\
\hline $\begin{array}{l}\text { (b) Change of marginal bone level (mm) } \\
\text { Implant placement - } 1 \text { year }\end{array}$ & Mean & & $-0.40 \pm 0.53$ & -0.22 & 0.49 & -1.73 to 0.14 & & $-0.41 \pm 0.66$ & -0.16 & 0.49 & -2.10 to 0.17 & 0.696 \\
\hline \multirow[t]{3}{*}{ Implant placement -3 years } & Mesial & 15 & $-0.21 \pm 0.62$ & 0.16 & 0.95 & -1.23 to 1.20 & 17 & $-0.33 \pm 0.78$ & 0.15 & 0.70 & -2.13 to 0.89 & 0.88 \\
\hline & Distal & & $-0.41 \pm 0.65$ & 0.26 & 0.43 & -1.88 to 0.34 & & $-0.48 \pm 1.15$ & 0.13 & 0.68 & -4.07 to 0.51 & 0.637 \\
\hline & Mean & & $-0.31 \pm 0.59$ & 0.21 & 0.59 & -1.55 to 0.67 & & $-0.40 \pm 0.93$ & 0.10 & 0.60 & -3.08 to 0.56 & 0.720 \\
\hline \multirow[t]{3}{*}{1 year -3 years } & Mesial & 15 & $0.17 \pm 0.37$ & -0.08 & 0.60 & -0.23 to 1.08 & 17 & $-0.01 \pm 0.35$ & -0.04 & 0.33 & -1.08 to 0.48 & 0.417 \\
\hline & Distal & & $-0.41 \pm 0.65$ & -0.01 & 0.54 & -1.88 to 1.94 & & $-0.08 \pm 0.65$ & -0.06 & 0.34 & -2.29 to 0.41 & 0.777 \\
\hline & Mean & & $0.14 \pm 0.59$ & -0.01 & 0.60 & -1.05 to 1.25 & & $-0.05 \pm 0.41$ & -0.04 & 0.26 & -1.12 to 0.43 & 0.692 \\
\hline
\end{tabular}


1 Table 2. Results of the clinical parameters at 3 years

Ti $4.1(n=15)$

\begin{tabular}{lrrrr} 
& \multicolumn{1}{c}{ Mean \pm SD } & Median & IQR & Range \\
\hline FMPS (\%) & $27.3 \pm 14.5$ & 22 & 20 & 12 to 65 \\
FMBS (\%) & $15.7 \pm 11.6$ & 12 & 16 & 0 to 36 \\
PCR (\%) & $10.0 \pm 16.4$ & 0 & 9 & 0 to 50 \\
BoP (\%) & $20.0 \pm 19.1$ & 17 & 33 & 0 to 67 \\
PPD (mm) & $2.9 \pm 0.8$ & 2.7 & 0.7 & 1.8 to 4.3 \\
KM (mm) & $2.8 \pm 1.1$ & 3 & 2 & 0 to 4
\end{tabular}

$\operatorname{Ti-Zr} 3.3(\mathrm{n}=17)$

\begin{tabular}{rrrrrr}
\hline \multicolumn{1}{r|}{ Mean \pm SD } & Median & IQR & Range & $\begin{array}{c}\text { p-value } \\
*\end{array}$ \\
\hline $19.6 \pm 12.0$ & 15 & 17 & 5 to 49 & 0.061 \\
$6.9 \pm 7.3$ & 4 & 9 & 0 to 24 & $0.028^{+}$ \\
$7.7 \pm 11.9$ & 0 & 17 & 0 to 33 & 0.911 \\
$13.8 \pm 17.9$ & 0 & 25 & 0 to 50 & 0.298 \\
$2.6 \pm 0.8$ & 3 & 1.3 & 1.2 to 3.7 & 0.732 \\
$3.2 \pm 1.1$ & 3 & 1.5 & 1 to 5 & 0.314 \\
\hline
\end{tabular}

* Results of Mann-Whitney test. Ti 4.1, titanium $4.1 \mathrm{~mm}$ diameter implants; Ti-Zr 3.3, titanium-zirconium $3.3 \mathrm{~mm}$ diameter implants; n, number; SD, standard deviation; IQR, interquartile range; FMPS, full-mouth plaque score; FMBS, full-mouth bleeding score; PCR, plaque control record; BOP, bleeding on probing; PPD, probing pocket depth; KM, width of keratinized mucosa. ${ }^{\dagger} p \leq 0.05$

4 Table 3. Results of (a) change in the mesial papilla level, (b) change in the distal papilla level 5 and (c) change in the mid-facial mucosa level from 6 months to 3 years (negative values 6 represent mucosal recession)

\begin{tabular}{|c|c|c|c|c|c|c|c|c|c|c|c|c|}
\hline & & \multicolumn{5}{|c|}{ Ti 4.1} & \multicolumn{5}{|c|}{ Ti-Zr 3.3} & p-value \\
\hline \multirow[t]{2}{*}{ (a) Change of the mesial papilla level } & 6 months to 1 year & 18 & $0.8 \pm 1.3$ & 0.3 & 2.0 & -1.0 to 3.0 & 19 & $0.5 \pm 1.4$ & 0.0 & 1.5 & -2.5 to 3.5 & 0.558 \\
\hline & 1 year to 3 years & 15 & $-0.2 \pm 1.4$ & 0.0 & 1.0 & -2.0 to 3.0 & 16 & $-0.3 \pm 0.8$ & 0.0 & 0.9 & -2.0 to 1.0 & 0.892 \\
\hline (b) Change of the distal papilla level & 1 year to 3 years & 15 & $-0.8 \pm 1.3$ & -0.5 & 2.0 & -4.0 to 1.0 & 16 & $-0.4 \pm 1.3$ & 0.0 & 1.0 & -4.0 to 2.0 & 0.401 \\
\hline \multirow[t]{3}{*}{ (c) Change of the mid-facial mucosa level } & 6 months to 1 year & 18 & $0.2 \pm 0.6$ & 0.0 & 0.6 & -1.0 to 1.5 & 19 & $0.0 \pm 0.8$ & 0.0 & 1.0 & -2.0 to 1.0 & 0.480 \\
\hline & 6 months to 3 years & 15 & $-0.3 \pm 1.1$ & 0.5 & 0.0 & -3.0 to 1.5 & 16 & $-0.3 \pm 0.9$ & -0.5 & 1.4 & -2.0 to 1.0 & 0.281 \\
\hline & 1 year to 3 years & 15 & $-0.5 \pm 0.8$ & 0.0 & 1.0 & -3.0 to 0.0 & 16 & $-0.2 \pm 0.4$ & 0.0 & 0.5 & -1.0 to 0.5 & 0.572 \\
\hline
\end{tabular}

Results of Mann-Whitney test for the inter-group analysis. Ti 4.1, titanium $4.1 \mathrm{~mm}$ diameter implants; Ti-Zr 3.3, titanium-zirconium $3.3 \mathrm{~mm}$ diameter

implants; $\mathrm{n}$, number; $\mathrm{SD}$, standard deviation ; IQR, interquartile range. 
1 Table S1. Patient demographics, distribution of implant locations and time points of implant

2 placement after tooth extraction (Benic et al., 2013).

Table S1. Patient demographics, distribution of implant locations and time points of implant placement after tooth extraction

\begin{tabular}{|c|c|c|c|}
\hline & Ti $4.1(n=20)$ & $\operatorname{TiZr} 3.3(n=20)$ & P-value* \\
\hline \multicolumn{4}{|l|}{ Gender, n (\%) } \\
\hline Male & $11(55)$ & $11(55)$ & 0.999 \\
\hline Female & $9(45)$ & $9(45)$ & \\
\hline \multicolumn{4}{|l|}{ Age (years) } \\
\hline Mean \pm SD & $51.5 \pm 14.1$ & $54.2 \pm 14.2$ & 0.327 \\
\hline Range & 21 to 80 & 25 to 75 & \\
\hline $95 \% \mathrm{CI}$ & $44.9 ; 58.1$ & $47.5 ; 60.9$ & \\
\hline Median & 51.0 & 61.5 & \\
\hline IQR & 16.5 & 17.0 & \\
\hline \multicolumn{4}{|c|}{ Smokers, n (\%) } \\
\hline No & $17(85)$ & $17(85)$ & 0.999 \\
\hline Yes & $3(15)$ & $3(15)$ & \\
\hline \multicolumn{4}{|l|}{ Site, n (\%) } \\
\hline Incisive & $2(10)$ & $1(5)$ & 0.766 \\
\hline Canine & $2(10)$ & $3(15)$ & \\
\hline Premolar & $16(80)$ & $16(80)$ & \\
\hline \multicolumn{4}{|l|}{ Jaw, n (\%) } \\
\hline Maxilla & $16(80)$ & $14(70)$ & 0.716 \\
\hline Mandible & $4(20)$ & $6(30)$ & \\
\hline \multicolumn{4}{|c|}{ Implantation time-point, $\mathrm{n}(\%)$} \\
\hline Type II & $1(5)$ & $3(15)$ & 0.472 \\
\hline Type III & $5(25)$ & $3(15)$ & \\
\hline Type IV & $14(70)$ & $14(70)$ & \\
\hline \multicolumn{4}{|c|}{$\begin{array}{l}\text { Ti 4.1, titanium } 4.1 \mathrm{~mm} \text {-diameter implants; TiZr 3.3, titanium-zirconium } 3.3 \mathrm{~mm} \text {-diameter implants; n, number; *, results of } \\
\text { Mann-Whitney and Chi2 tests; SD, standard deviation; } 95 \% \mathrm{CI} \text {, 95\% confidence interval; IQR, interquartile range }\end{array}$} \\
\hline
\end{tabular}

\begin{tabular}{|c|c|c|c|}
\hline & $\operatorname{Ti} 4.1(n=20)$ & Ti-Zr $3.3(n=20)$ & $p$-value * \\
\hline \multicolumn{4}{|c|}{ Peri-implant bone defect $\mathbf{n}(\%)$} \\
\hline no & $13(65)$ & $13(65)$ & 0.999 \\
\hline yes & $7(35)$ & $7(35)$ & \\
\hline \multicolumn{4}{|c|}{ Bone augmentation $\mathrm{n}(\%)$} \\
\hline no & $11(55)$ & $10(50)$ & 0.999 \\
\hline yes & $9(45)$ & $10(50)$ & \\
\hline
\end{tabular}

* Results of Mann-Whitney test. Ti 4.1, titanium $4.1 \mathrm{~mm}$ diameter implants; Ti-Zr 3.3, titanium-zirconium

$3.3 \mathrm{~mm}$ diameter implants; $\mathrm{n}$, number 


\section{Figures}

4 Figure 1. Time sequence of interventions and examinations.

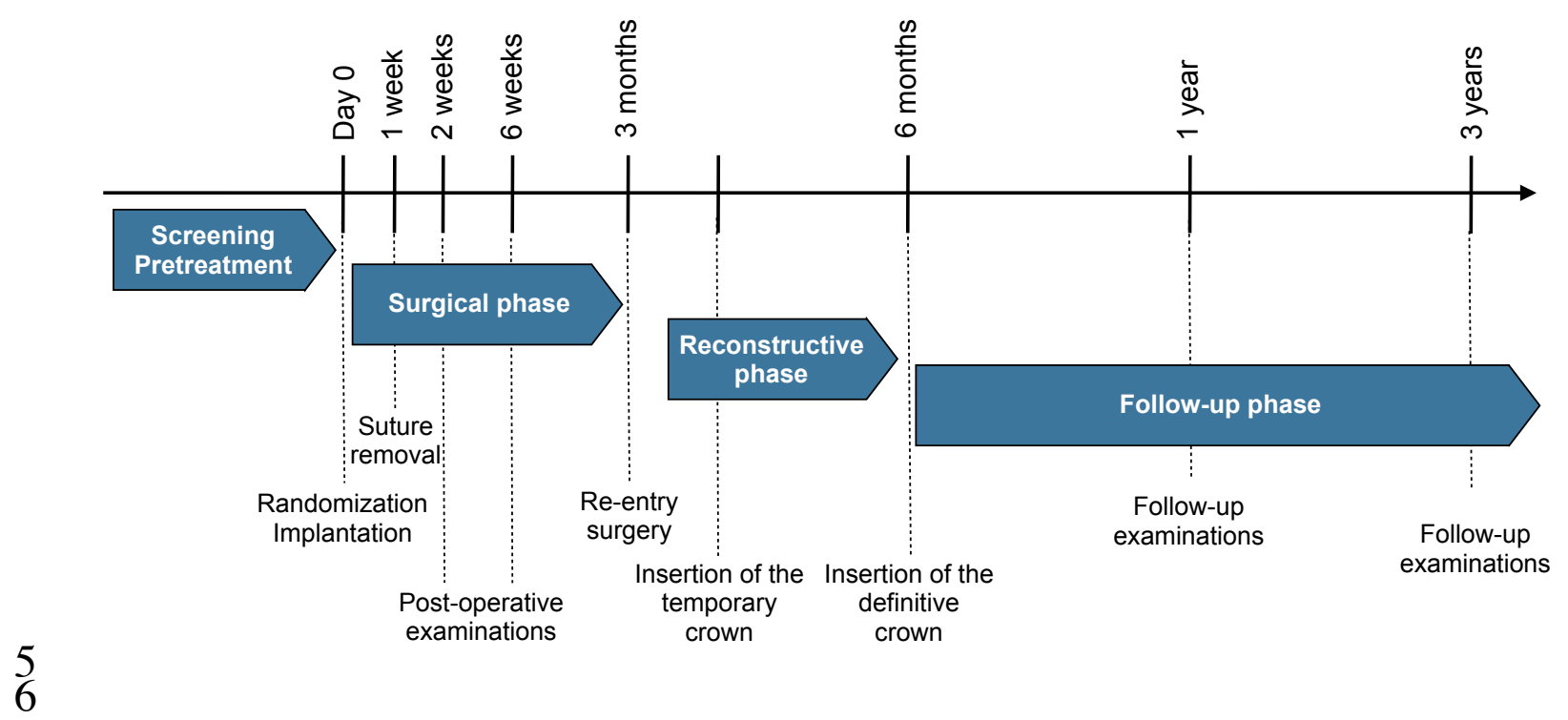


1 Figure 2. (a) Intra-operative situation of site 13 after the placement of a titanium-zirconium 2 implant with $3.3 \mathrm{~mm}$ diameter. (b) Occlusal view after the soft tissue healing. (c) Occlusal 3 view and (d) facial view after the insertion of the definitive porcelain-fused-to-metal crown. (e)

4 Occlusal view, (f) facial view and (g) periapical radiograph at the 3-year follow-up.
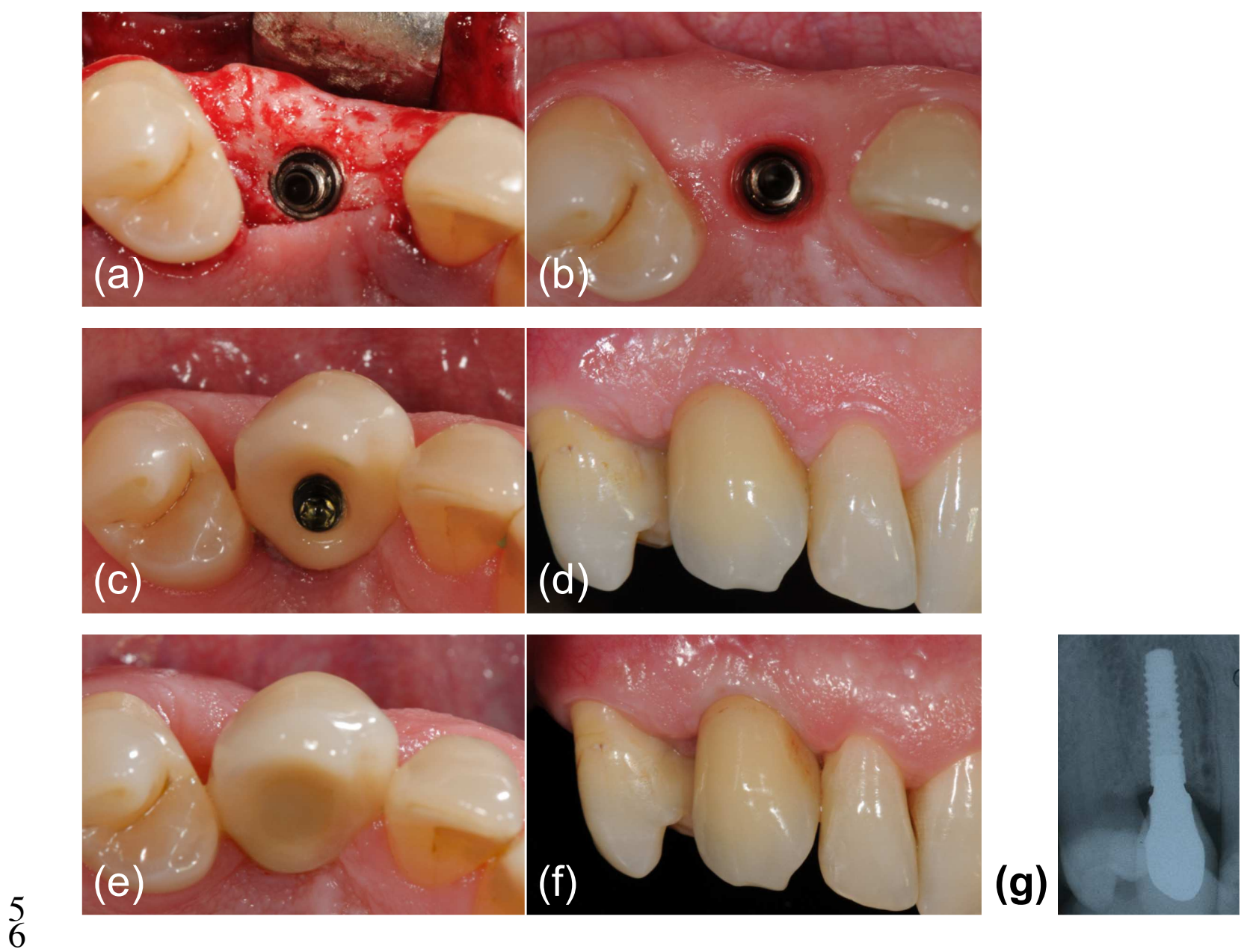
1 Fig. 3. Box plots representing the mean marginal bone levels (in $\mathrm{mm}$ ) relative to the implant

2 shoulder at the implant placement, at 6 months, at 1 year and at 3 years (a) in the titanium

$34.1 \mathrm{~mm}$ diameter ( $\mathrm{Ti} 4.1$ ) and (b) in the titanium-zirconium $3.3 \mathrm{~mm}$ diameter ( $\mathrm{Ti}-\mathrm{Zr} \mathrm{3.3)}$

4 groups. Box plots depicting the change of mean marginal bone level (in $\mathrm{mm}$ ) from the implant

5 placement to 3 years and from 1 year to 3 years (c) in the Ti 4.1 and (d) in the $\operatorname{Ti}-\mathrm{Zr} 3.3$

6 groups. $^{\circ}$ and ${ }^{*}$ in the figure represent the outliers.

Ti $4.1 \mathrm{~mm}$

(a)

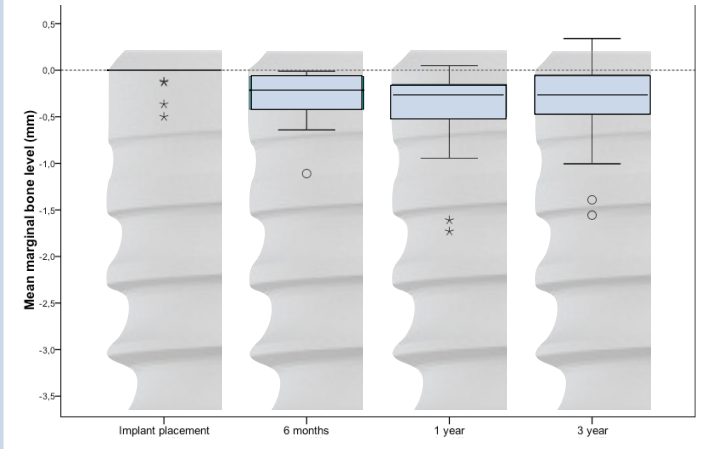

(c)

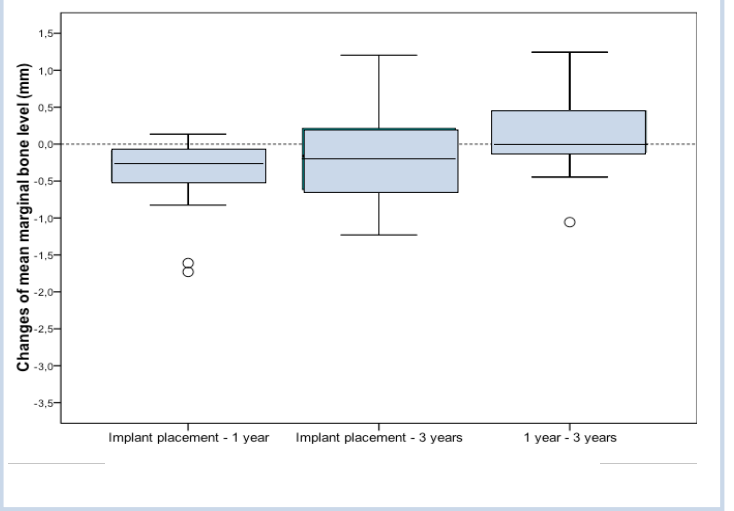

Ti-Zr 3.3 mm

(b)

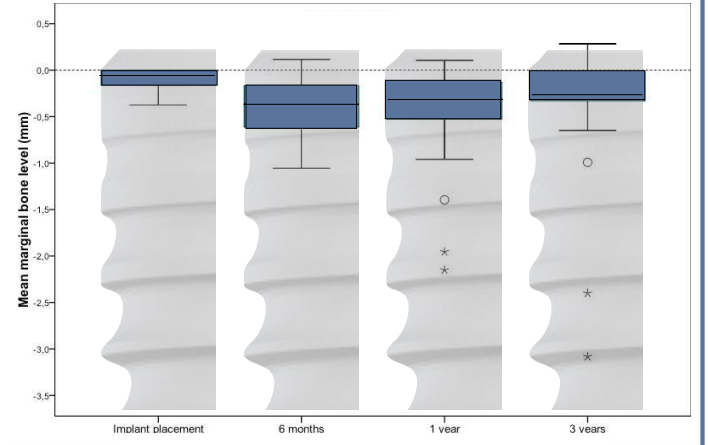

(d)

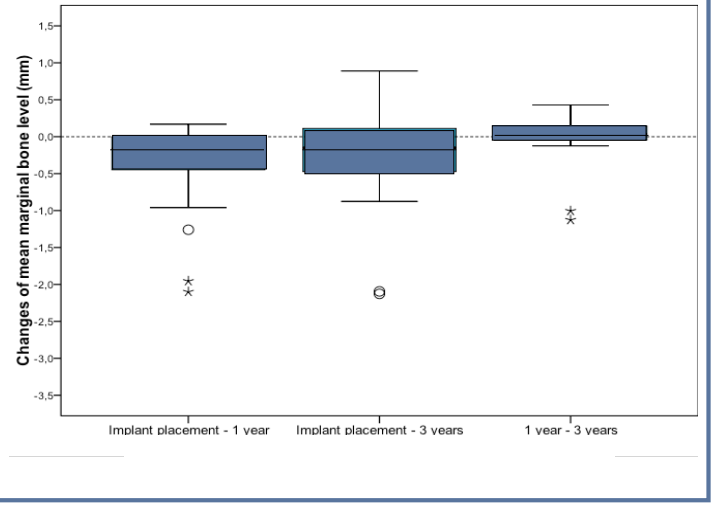


1 Figure 4. Frequency distributions of the changes in (a) mesial, (b) distal and (c) mean 2 marginal bone level (in $\mathrm{mm}$ ) from the implant placement to the 3-year examination.

3

(a) Change in mean marginal bone level from implant placement to 3 years

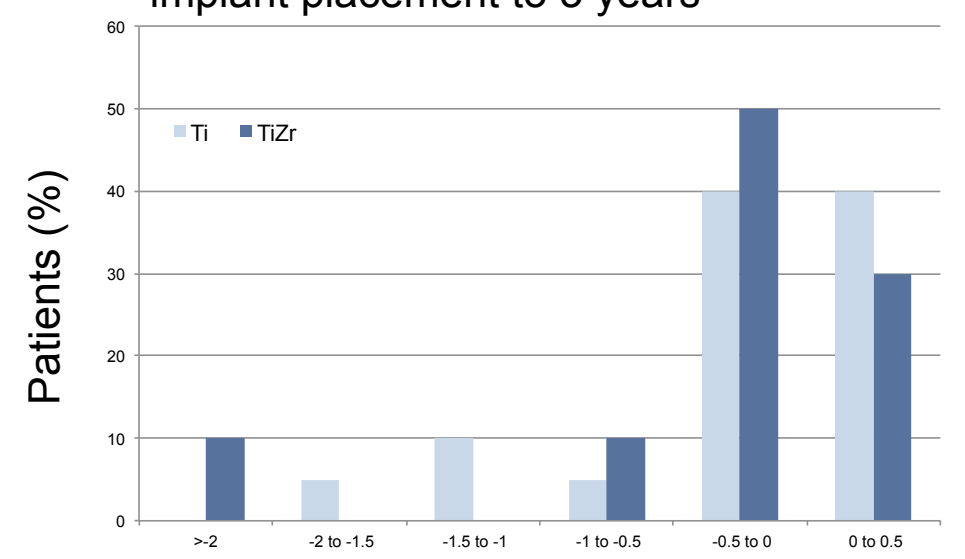

(b) Change in mesial marginal bone level from implant placement to 3 years

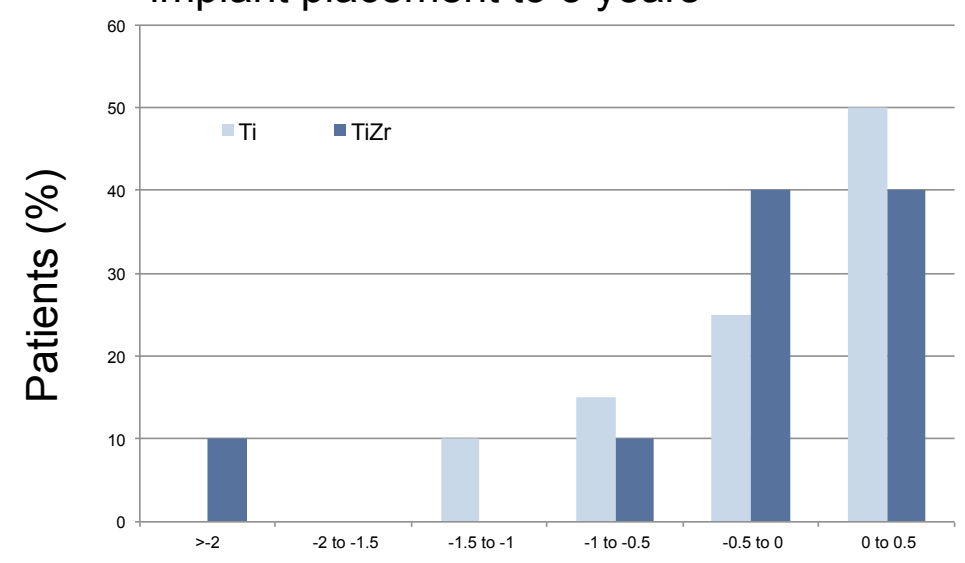

(c) Change in distal marginal bone level from implant placement to 3 years

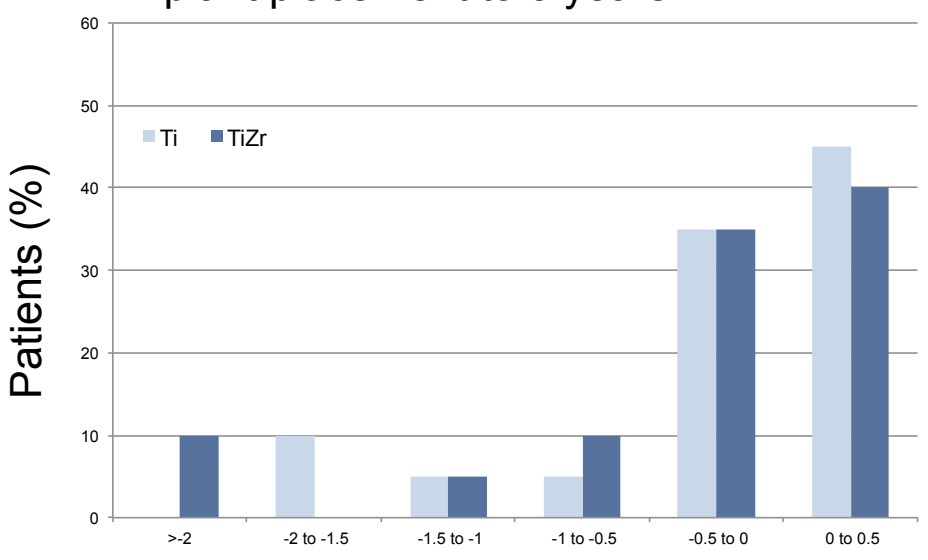




\section{References}

Ainamo, J. \& Bay, I. (1975) Problems and proposals for recording gingivitis and plaque. International Dental Journal 25, 229-235.

Al-Nawas, B., Bragger, U., Meijer, H. J., Naert, I., Persson, R., Perucchi, A., Quirynen, M., Raghoebar, G. M., Reichert, T. E., Romeo, E., Santing, H. J., Schimmel, M., Storelli, S., ten Bruggenkate, C., Vandekerckhove, B., Wagner, W., Wismeijer, D. \& Muller, F. (2012) A double-blind randomized controlled trial (RCT) of Titanium-13Zirconium versus Titanium Grade IV small-diameter bone level implants in edentulous mandibles--results from a 1-year observation period. Clinical Implant Dentistry and Related Research 14, 896-904. doi:10.1111/j.17088208.2010.00324.x.

Anchieta, R. B., Baldassarri, M., Guastaldi, F., Tovar, N., Janal, M. N., Gottlow, J., Dard, M., Jimbo, R. \& Coelho, P. G. (2013) Mechanical Property Assessment of Bone Healing around a Titanium-Zirconium Alloy Dental Implant. Clinical Implant Dentistry and Related Research. doi:10.1111/cid.12061.

Barter, S., Stone, P. \& Bragger, U. (2012) A pilot study to evaluate the success and survival rate of titanium-zirconium implants in partially edentulous patients: results after 24 months of follow-up. Clinical Oral Implants Research 23, 873-881. doi:10.1111/j.1600-0501.2011.02231.x.

Benic, G. I., Gallucci, G. O., Mokti, M., Hammerle, C. H., Weber, H. P. \& Jung, R. E. (2013) Titanium-zirconium narrow-diameter versus titanium regular-diameter implants for anterior and premolar single crowns: 1-year results of a randomized controlled clinical study. Journal of Clinical Periodontology 40, 1052-1061. doi:10.1111/jcpe.12156.

Benic, G. I. \& Hammerle, C. H. (2014) Horizontal bone augmentation by means of guided bone regeneration. Periodontology 2000 66, 13-40. doi: $10.1111 /$ prd.12039.

Benic, G. I., Jung, R. E., Siegenthaler, D. W. \& Hammerle, C. H. (2009) Clinical and radiographic comparison of implants in regenerated or native bone: 5-year results. Clinical Oral Implants Research 20, 507-513. doi:10.1111/j.1600-0501.2008.01583.x.

Berner, S., Dard, M., Gottlow, J., Molenberg, A. \& Wieland, M. (2009) Titanium-Zirconium: A Novel Material for Dental Implants. European Cells and Materials 17, 16.

Buser, D., Weber, H. P. \& Lang, N. P. (1990) Tissue integration of nonsubmerged implants. 1-year results of a prospective study with 100 ITI hollow-cylinder and hollow-screw implants. Clinical Oral Implants Research 1, 33-40.

Caneva, M., Salata, L. A., de Souza, S. S., Baffone, G., Lang, N. P. \& Botticelli, D. (2010) Influence of implant positioning in extraction sockets on 
osseointegration: histomorphometric analyses in dogs. Clinical Oral Implants Research 21, 43-49. doi:10.1111/j.1600-0501.2009.01842.x.

Chiapasco, M., Casentini, P., Zaniboni, M., Corsi, E. \& Anello, T. (2012) Titanium-zirconium alloy narrow-diameter implants (Straumann Roxolid((R))) for the rehabilitation of horizontally deficient edentulous ridges: prospective study on 18 consecutive patients. Clinical Oral Implants Research 23, 1136-1141. doi:10.1111/j.16000501.2011.02296.x.

Davarpanah, M., Martinez, H., Tecucianu, J. F., Celletti, R. \& Lazzara, R. (2000) Small-diameter implants: indications and contraindications. Journal of Esthetic Dentistry 12, 186-194.

Esposito, M., Ekestubbe, A. \& Grondahl, K. (1993) Radiological evaluation of marginal bone loss at tooth surfaces facing single Branemark implants. Clinical Oral Implants Research 4, 151-157.

Gottlow, J., Dard, M., Kjellson, F., Obrecht, M. \& Sennerby, L. (2012) Evaluation of a new titanium-zirconium dental implant: a biomechanical and histological comparative study in the mini pig. Clinical Implant Dentistry and Related Research 14, 538-545. doi:10.1111/j.17088208.2010.00289.x.

Grandin, H. M., Berner, S. \& Dard, M. (2012) A review of titanium zirconium (TiZr) alloys for use in endosseous dental implants. Materials 5, 13481360 .

Hammerle, C. H., Chen, S. T. \& Wilson, T. G., Jr. (2004) Consensus statements and recommended clinical procedures regarding the placement of implants in extraction sockets. International Journal of Oral and Maxillofacial Implants 19 Suppl, 26-28.

Hammerle, C. H., Jung, R. E. \& Feloutzis, A. (2002) A systematic review of the survival of implants in bone sites augmented with barrier membranes (guided bone regeneration) in partially edentulous patients. Journal of Clinical Periodontology 29 Suppl 3, 226-231; discussion 232-223.

Jung, R. E., Fenner, N., Hammerle, C. H. \& Zitzmann, N. U. (2013) Long-term outcome of implants placed with guided bone regeneration (GBR) using resorbable and non-resorbable membranes after 12-14 years. Clinical Oral Implants Research 24, 1065-1073. doi:10.1111/j.16000501.2012.02522.x.

Jung, R. E., Zembic, A., Pjetursson, B. E., Zwahlen, M. \& Thoma, D. S. (2012) Systematic review of the survival rate and the incidence of biological, technical, and aesthetic complications of single crowns on implants reported in longitudinal studies with a mean follow-up of 5 years. Clinical Oral Implants Research 23 Suppl 6, 2-21. doi:10.1111/j.16000501.2012.02547.x.

Klein, M. O., Schiegnitz, E. \& Al-Nawas, B. (2014) Systematic review on success of narrow-diameter dental implants. International Journal of Oral 
doi:10.11607/jomi.2014suppl.g1.3.

Kobayashi, E., Matsumoto, S., Doi, H., Yoneyama, T. \& Hamanaka, H. (1995) Mechanical properties of the binary titanium-zirconium alloys and their potential for biomedical materials. Journal of Biomedical Materials Research 29, 943-950. doi:10.1002/jbm.820290805.

Mayfield, L., Skoglund, A., Nobreus, N. \& Attstrom, R. (1998) Clinical and radiographic evaluation, following delivery of fixed reconstructions, at GBR treated titanium fixtures. Clinical Oral Implants Research 9, 292302.

Moher, D., Hopewell, S., Schulz, K. F., Montori, V., Gotzsche, P. C., Devereaux, P. J., Elbourne, D., Egger, M. \& Altman, D. G. (2010) CONSORT 2010 Explanation and Elaboration: Updated guidelines for reporting parallel group randomised trials. Journal of Clinical Epidemiology 63, e1-37. doi:10.1016/j.jclinepi.2010.03.004.

O'Leary, T. J., Drake, R. B. \& Naylor, J. E. (1972) The plaque control record. Journal of Periodontology 43, 38. doi:10.1902/jop.1972.43.1.38.

Papadimitriou, D. E., Friedland, B., Gannam, C., Salari, S. \& Gallucci, G. O. (2014) Narrow-Diameter versus Standard-Diameter Implants and Their Effect on the Need for Guided Bone Regeneration: A Virtual ThreeDimensional Study. Clinical Implant Dentistry and Related Research. doi:10.1111/cid.12224.

Quirynen, M., Al-Nawas, B., Meijer, H. J., Razavi, A., Reichert, T. E., Schimmel, M., Storelli, S., Romeo, E. \& the Roxolid Study, G. (2014) Small-diameter titanium Grade IV and titanium-zirconium implants in edentulous mandibles: three-year results from a double-blind, randomized controlled trial. Clinical Oral Implants Research. doi:10.1111/clr.12367.

Sanz, M., Chapple, I. L. \& Working Group 4 of the, V. E. W. o. P. (2012) Clinical research on peri-implant diseases: consensus report of Working Group 4. Journal of Clinical Periodontology 39 Suppl 12, 202-206. doi:10.1111/j.1600-051X.2011.01837.x.

Saulacic, N., Bosshardt, D. D., Bornstein, M. M., Berner, S. \& Buser, D. (2012) Bone apposition to a titanium-zirconium alloy implant, as compared to two other titanium-containing implants. Eur Cell Mater 23, 273-286; discussion 286-278.

Tarnow, D. P., Cho, S. C. \& Wallace, S. S. (2000) The effect of inter-implant distance on the height of inter-implant bone crest. Journal of Periodontology 71, 546-549. doi:10.1902/jop.2000.71.4.546.

Thoma, D. S., Jones, A. A., Dard, M., Grize, L., Obrecht, M. \& Cochran, D. L. (2011) Tissue integration of a new titanium-zirconium dental implant: a comparative histologic and radiographic study in the canine. Journal of Periodontology 82, 1453-1461. doi:10.1902/jop.2010.100737.

Tolentino, L., Sukekava, F., Seabra, M., Lima, L. A., Garcez-Filho, J. \& Araujo, M. G. (2014) Success and survival rates of narrow diameter implants 
made of titanium-zirconium alloy in the posterior region of the jaws results from a 1-year follow-up. Clinical Oral Implants Research 25, 137 141. doi:10.1111/clr.12113.

Wen, B., Zhu, F., Li, Z., Zhang, P., Lin, X. \& Dard, M. (2013) The osseointegration behavior of titanium-zirconium implants in ovariectomized rabbits. Clinical Oral Implants Research. doi:10.1111/clr.12141.

Zinsli, B., Sagesser, T., Mericske, E. \& Mericske-Stern, R. (2004) Clinical evaluation of small-diameter ITI implants: a prospective study. International Journal of Oral and Maxillofacial Implants 19, 92-99.

Zumstein, T., Billstrom, C. \& Sennerby, L. (2012) A 4- to 5-year retrospective clinical and radiographic study of Neoss implants placed with or without GBR procedures. Clinical Implant Dentistry and Related Research 14, 480-490. doi:10.1111/j.1708-8208.2010.00286.x. 


\section{Clinical Relevance}

2 Scientific rationale for the study: Narrow-diameter implants were introduced to overcome

3 clinical situations with reduced bone width bucco-orally or a narrow mesio-distal tooth-gap.

4 The strength of narrow-diameter titanium implants however is limited and thus implant

5 fractures may occur. By alloying titanium to other metals like zirconium (titanium-zirconium),

6 the strength of narrow-diameter implants can be improved.

7 Principal findings: Narrow-diameter $(3.3 \mathrm{~mm})$ titanium-zirconium implants did not perform

8 differently from regular-diameter $(4.1 \mathrm{~mm})$ titanium implants regarding the change in marginal

9 bone level from the implant placement to the 3-year examination. During this observation

10 period there were no implant failures. Furthermore, there were no significant differences

11 between the groups with respect to clinical parameters and occurrences of adverse events.

12 Practical implications: The use of titanium-zirconium narrow-diameter implants for the

13 support of single crowns in the anterior and premolar regions leads to successful tissue

14 integration and clinical performance over a 3-year period. Longer observation periods are

15 required to recommend the use of titanium-zirconium implants with narrow diameter for this

16 clinical indication. 